\title{
Tensions in intergenerational practice guidance: intergroup contact versus community development
}

\author{
By Katie Wright-Bevans*, Michael Murray* $\mathcal{E}$ \\ ALEXANDRA LAMONT*
}

\begin{abstract}
Intergenerational practice (IP) is an approach within community health promotion which aims to bring older and younger community members together in collaborative activity. Little research has critically examined the assumptions and values within IP and their implications for these communities. A sample of 15 IP planning documents were analysed using a social constructionist thematic analysis (Braun \& Clarke2006) guided by Prior's (2008) concept of documents as active agents. Three tensions were identified: a community-led model versus a contact model; old and young as targets versus older people as targets; and process-focused versus outcome-focused evaluation. IP has relied on contact theory as a mechanism of change, which has rooted IP to an overly individualistic practice targeted at older people (rather than all ages). In contrast, the community-led ethos of IP was also evident alongside values of mutual benefit for old and young, and a desire for more process-focused evaluation.
\end{abstract}

Keywords: community, guidance, health, intergenerational, document analysis, ageing, social representations.

${ }^{*}$ Katie Wright-Bevans, Michael Murray \& Alexandra Lamont, School of Psychology, Keele University, Staffordshire, UK 
International Journal of Ageing and Later Life

\section{Introduction}

Intergenerational practice (IP) is an approach within community health promotion which aims "to bring people together in purposeful, mutually beneficial activities which promote greater understanding and respect between generations and contribute to building more cohesive communities" (Beth Johnson Foundation 2011). Initiatives may involve a broad range of creative, social or skills-based activities such as arts, befriending or gardening. Governments have endorsed the use of IP as a means of promoting more cohesive communities (Statham 2009).

Detailed guidance on how to implement IP has been developed by various organisations in the United Kingdom (UK) and elsewhere in recent years as the practice has become increasingly formalised. Toolkits, practice literature and organisations supporting IP have also grown, as have the number and range of projects (Henkin \& Butts 2002). Despite this, the assumptions underlying the guidance and practice have received very little empirical attention.

The aims and objectives of organisations implementing IP vary; however, a common focus is the promotion of community cohesion, intergenerational contact and knowledge exchange (Buffel et al. 2014). Across the UK, the United States and the mainland Europe (where IP is equally prevalent), health professionals have recognised the value of social engagement for older people, and research has witnessed a steady shift away from combatting individual barriers to social engagement, such as cognitive decline, towards ways to promote active ageing involving social connections (Sampson et al. 2009). The development and increasing popularity of IP also map onto a growing trend of citizenship programmes for young people in the UK, many of which aim to promote community participation and address health and social issues (Haste 2004).

\section{The Dominance of Contact Theory in IP}

Health-promotion programmes are most likely to benefit individuals and communities when guided by social and behavioural science theories (Kok et al. 2004). Kok et al. (2004) noted that theory-driven healthpromotion programmes require an understanding of the operational or 
practical forms of such theories. These may be applicable to behaviour at one or more levels: individual, interpersonal, organisational, community and society, and whilst students are taught to apply theories to problems, practitioners work in the opposite direction. They have to find useful theories to help understand and address problems. Kok et al. (2004) argued that the application of theory has been a challenge for health-promotion researchers and practitioners and too often, theories, prior evidence and programme objectives are mis-aligned, resulting in either ineffective interventions or successful programmes where the mechanisms for change are unclear. The aim of this article is to critique the theory underlying the practice of IP.

Contact theory, which works on an individual and interpersonal level, has been cited consistently and extensively in IP research and evaluation (e.g. Abrams et al. 2006; Alcock et al. 2011; Gaggioli et al. 2014; Grefe 2011). A content analysis of 128 studies of IP revealed that research is largely underpinned by contact theory or variations of it (Jarrott 2011). The many variations of contact theory all have their basis in Allport's (1954) contact hypothesis, a social psychological theory, rooted in the idea that prejudice stems from an inability to identify with those who are different (out-group members) from us (in-group members). The theory predicts that positive inter-group contact (i.e. contact between in-group and out-group members) results in positive inter-group relations and reduced prejudice. Such changes in prejudice are frequently measured through attitude scales before and after contact interventions (Hewstone \& Swart 2011).

Reviews of over 200 examples of IP (Granville 2002; MacCallum et al. 2006) concluded that IP can have a broad range of health and social benefits for individuals and communities beyond attitude change. Critical commentaries on IP are plentiful (e.g. Bernard \& Ellis 2004; Granville 2002; Knight 2012; Statham 2009). Each suggested that IP needs greater theoretical and practical attention in order for it to reach its full potential as a community health-promotion tool.

The over reliance on contact theory has also resulted in a neglect of research into processes of change. In a paper by Bernard and Ellis (2004), titled "How do we know that intergenerational practice works?," it was concluded that the mechanisms behind successful practice are still largely 
International Journal of Ageing and Later Life

unclear. A recent review attempted to address this gap by analysing the mechanisms behind 31 studies of IP (Drury et al. 2017). However, this review was also driven by contact theory and although it identified some of the mechanisms behind successful intergenerational contact (e.g. equal status, extended contact), this review neglected the political, social and cultural contexts within which IP is conducted, reviewing mechanisms of contact in isolation of wider practices.

The narrowing of attention to quantifiable measures of individual change is a common feature of health-promotion programmes (Sykes et al. 2004). Although this approach to capturing evidence is inevitably more resource-light, this approach hinders the advancement of health promotion, as it only values one type of research and evaluation. Health-promotion evaluation that relies solely on surveys and scales to determine its success or failure is inadequate for several reasons. It is highly individualistic in the sense that the focus is on individual change rather than social change. It also values evaluations of outcomes and not processes or mechanisms of change. Contact theory falls within the dominant individualistic psychological approach which draws upon "the same rationalistic assumptions" (Markova 2007: 232) as other theories commonly employed in health-promotion programmes such as the Theory of Planned Behaviour (Fishbein \& Ajzen 1974). Contact theories and individualist measurement tools have masked the role of community- and societal-level factors in shaping and constraining the capacity of IP.

\section{Critical Approaches to Community Health Promotion}

New public health tools such as community health promotion adopt a more value-laden and political perspective (Petersen \& Lupton 1996). Although defined as a community development tool, IP has not been approached as such by most scholars to date. There is a need for more critical empirical examination of the nature of IP in order to examine the assumptions and values that drive practice, rather than simply the most appropriate mechanisms or outcomes of contact. Such investigation would allow researchers and practitioners to look beyond attitude change and gain insight into how IP works, who it benefits and in what way. 
Other community health-promotion tools and social change initiatives, which have been investigated more critically, demonstrate how a more critical approach can provide insights into how practices are constructed. These benefits are illustrated in two rather different yet noteworthy examples. Campbell and Cornish (2010) identified four approaches to behaviour change in HIV/AIDS interventions: top-down information provision, peer-based, whole community and community mobilisation. The approaches range from more individualistic apolitical approaches to behaviour change, to more political community-led approaches. Campbell and Cornish (2010) argued that only the latter are effective in the longterm, and even then community mobilization approaches need support from individuals and agencies both outside and within the community.

In a similarly critical manner, Maoz (2012) examined models of social change in the context of encounters between Israeli Jews and Palestinians. He identified four models: coexistence (groups working together yet with little interaction), joint projects (groups work together), confrontational (groups work together and acknowledge power dynamics) and narrative-story-telling (groups work together to share stories with each other and the wider community). Maoz (2012: 278)argued that the fourth narrative-story-telling model had the greatest potential for fostering actual and lasting social change. This model "combines interpersonal interaction with interaction through group identities and the forming of personal ties with discussions of the conflict and of power relations."

By dissecting respective health and social interventions both Campbell and Cornish (2010) and Maoz (2012) shed light on the assumptions and values within different practices and allowed for closer scrutiny of various approaches to interventions and the impact of these. There is potential value in applying a similarly critical lens to the study of IP as a community health-promotion tool to illuminate its assumptions and values.

\section{Documents as Active Agents}

This study drew upon Prior's (2006) concept of documents as active agents to conduct a critical examination of IP documents in the UK. Prior argued 
International Journal of Ageing and Later Life

that documents are not simply containers of information, instead they are active agents, embedded with the assumptions and values of those who create them. By recognising the social and political role of the documents that guide IP, these can be subject to a more critical empirical investigation and recognised as a terrain in which concepts surrounding IP are constructed or contested.

Social constructionist analyses of health-related policy and documentation have provided a deeper understanding of how other health issues operate in practice. Brisbois and Plamondon (2018) in a noteworthy recent example analysed a selection of global health research documents and identified contrasting representations of the world in which global health research is taking place. Their research highlighted the ways in which damaging representations could impact the health of communities.

\section{Social Representation Theory}

This study drew on the social representation theory (SRT) (Moscovici1988) to understand the assumptions and values constructed and contested in IP documents. SRT has been used to help understand meaning-making regarding such phenomena as health and illness (Murray et al. 2003), ageing (Moreno et al. 2016) and technology (e.g. Kalampalikis et al. 2013). Such studies have demonstrated how social representations shape experiences and action. Social representations are the shared assumptions and values of a community which are shared through everyday communication. The earliest research done by Moscovici (1988) explored how social representations were reflected in popular newspapers. Since then, there have been many studies on social representations of different phenomena in different media (e.g. Höijer 2011). However, there has been less research on the content of scientific communications such as in official documents.

As SRT is critical in its version of social constructionism, recognising that knowledge, whether lay or expert, is neither apolitical nor value-free, it is particularly well aligned with Prior's (2006) concept of documents as active agents.There has not been any research to empirically examine IP guidelines in the UK. This article complements and extends the work of others (Granville 2002; Knight 2012; Larkin \& Rosebrook 2003; Statham 2009) by offering insight into how IP in the UK is constructed and the implications of those meanings for practice. 
The aim of this study was not to synthesise guidelines or identify effective practices in an objective manner. Instead, this study sought to explore the ways in which IP documents socially construct and conceptualise IP. Furthermore, we sought to understand the implications of these constructions for practice. In doing so, the following two key research questions guided our analysis:

- How do IP documents conceptualise IP?

- What do conceptualisations of IP suggest about the nature of the practice?

\section{Methods}

\section{Document Sample}

The search strategy aimed to gain a representative sample of the most accessible documents, rather than the most detailed or up-to-date ones. Documents were initially selected based on ease of availability to the UK facilitators of IP. All documents considered were publicly available and accessed freely over the Internet between Spring 2014 and Summer 2018. As documents were accessed through a public forum, it was not necessary to seek permission for their analysis. The search strategy involved searching, using Google, for documents and guidance, including the word "intergenerational" alongside the following search terms: "practice," "guide," "approach," "strategy" and "toolkit." This search strategy allowed for the inclusion of any relevant documents that used the term "intergenerational" but not necessarily the term "practice." Those which appeared high in search results were scanned for suitability. Case study reports and evaluations rather than guides to practice were excluded. After judging documents against these inclusion and exclusion criteria, a total of 15 documents, including a total of 359 pages of text and images, remained for analysis.

It was made clear that the guidelines were aimed at facilitators through the use of such phrases as "aimed at those new to setting up intergenerational projects" and "aimed at people working in community development, neighbourhood management, and regeneration." The final selection of documents came from diverse local government sources and charitable 
International Journal of Ageing and Later Life

Table 1. Key features of the documents sampled

\begin{tabular}{lll}
\hline $\begin{array}{l}\text { Author: National } \\
\text { charity (NC) or } \\
\text { local authority (LA) }\end{array}$ & Target audience & $\begin{array}{l}\text { Target } \\
\text { community }\end{array}$ \\
\hline NC & $\begin{array}{ll}\text { Community facilitators } \\
\text { "Those new to setting up intergenerational } \\
\text { NC }\end{array}$ & $\begin{array}{l}\text { Older people } \\
\text { projects" }\end{array}$ \\
NC & "Those working with community groups" & All ages \\
NC & Community workers & All ages \\
NC & Community workers & Older people \\
LA & Neighbourhood regeneration officers & All ages \\
LA & Intergenerational officers & Older people \\
LA & Community project managers & Older people \\
LA & Community workers & All ages \\
LA & Community workers & All ages \\
LA & Community project facilitators & All ages \\
LA & Community workers & Younger people \\
LA & Community workers & Older people \\
LA & Community development officers & Older people \\
LA & Not specified & All ages \\
\hline
\end{tabular}

organisations, but all were created with an aim of providing guidance on practice to potential IP facilitators (see Table 1).

\section{Analysis of Content and Function}

All content was subjected to a social constructionist thematic analysis (Braun \& Clarke 2006), where the analytic lens was broad, including function as well as content as advocated by Prior (2003). The analysis took a social constructionist stance in the sense that it strove to "identify and examine underlying ideas, assumptions and conceptualisations" (Braun \& Clarke 2006: 84). In line with the theory of social representations, the analytic focus was on exploring underlying assumptions and shared ideas 
rather than any perceptions held by individual document authors. The identification of themes was driven by both a desire to capture the core content of the codes and the common sense understanding that underpinned them.

The analysis of function was conducted in tandem with the thematic analysis. This aspect of the analysis considered the context within which the documents were constructed. This process required questions to be addressed such as "who is the author, what purpose does this document serve for them?" and "who is the target audience?" The answers to these questions (e.g. documents are aimed at facilitators working to help manage older people) were then integrated into the themes derived from the content of the documents. The marrying of thematic analysis (Braun \& Clarke 2006) and document analysis (Prior 2008) allowed the research aims to be addressed in a more critical and context-sensitive manner.

\section{Findings}

Three primary dimensions were used to characterise the content of 15 documents. The structure of these dimensions are shown in Figure 1.

\section{Community-Led Model versus Contact Model of IP}

The majority of documents contained descriptions of how IP was believed to work as a community-led approach in which the practice must be developed from the community's interests, needs and agenda. In one guidance

Figure 1. Three primary dimensions characterising IP.

\begin{tabular}{|c|c|}
\hline Community-led model & Contact model \\
\hline Old and young as targets & Older people as targets \\
\hline Process-focused evaluation & Outcome-focused evaluation \\
\hline
\end{tabular}


International Journal of Ageing and Later Life

document, the value of bringing the community together to communicate these interests was emphasised:

UNDERSTANDING THE PROCESS. When creating new ideas, bring together the people with the first-hand insight and experience to identify the opportunities and add their perspective to the creative process. This will be about bringing together different generations and facilitating joint conversations and activities. You cannot possibly have all the best ideas alone. (Document 1, p. 17)

The process of implementing IP was described as the act of bringing together young and old in order for the IP facilitator to listen to multiple perspectives. IP was described as a community-led process where the community members were valued for their first-hand insight and experience. In this bottom-up process, the facilitators gathered information and ideas from the community rather than implement their own agenda or rely on intergenerational contact alone as a tool for success. This might involve identifying goals and expectations or might be a freer process with no predetermined end.

Despite descriptions of IP placing emphasis on community needs and action, where the documents outlined practical steps, contact was a central concept throughout the documents and not only in step-by-step guidance on bringing old and young participants together. Here, contact was discussed as a framework whereby local implementation could be tracked: "It is useful to see its local implementation as a continuum that tracks the levels of contact with and between participating generations" (Document 1, p. 5). Throughout the documents, these two ways of constructing IP could be seen in tension. On the one hand, IP was described as an agent of community change, but, on the other, the mechanism through which this was believed to work was through "connecting the generations." Whilst IP would inevitably involve intergenerational contact, this approach was highly problematic in its neglect of the community resources that would be needed to achieve change and in its assumption that contact alone would allow communities to be revitalised. In omitting these wider community factors, the onus and responsibility was implicitly placed on individuals to achieve change.

Some documents were more reflexive in their practice guidance than others. The following example illustrates how some documents warned against being too prescriptive: 
There are a number of definitions, toolkits and manuals around as Intergenerational Practice pushes its way to the top of the agenda, however throughout this process it is important to remember to listen to your communities and run your projects in line with their wants and needs. (Document 5, p. 3)

This document reminded facilitators of the need to listen to their communities, suggesting that this might be difficult or conflicting with other agendas such as those of funders. Such responsible practice might be challenging when in theory, much practice is based on the assumption that contact alone would provide a route to community change.

\section{Old and Young as Targets versus Older People as Targets}

All documents included at least some discussion of who IP was targeted at. Two approaches strongly emerged. The first constructed IP as all-age friendly and targeted both young and old. The second constructed IP as targeted at older people, with little, if any, mention of younger people. Some of the documents emphasised age equality as a core value of IP:

Intergenerational practice is based on the principle that older and younger people work together in an equal power relationship, for their benefit and the benefit of their local community. By giving people a time, place and structure to do this, it helps different generations share their past, present and hopes for the future. (Document 11, p. 5)

Age equality and mutual benefit were promoted as a foundational principle of IP. Furthermore, IP did not simply involve both young and old benefiting but also involved the establishment of equal power relationships. The nature of the equal involvement of participants was emphasised, rather than simply who should be targeted to participate. This example is typical of half the sample in that it explicitly emphasised the all-age friendly nature of IP, where both young and old should have the space to engage, learn and share in a reciprocal way.

Despite mutual benefit being core to the definition of IP, the idea that IP was for older people was a dominant construction in these documents. One document illustrated this construct clearly and succinctly through its title: Strategy for older people in Wales: A Strategy for intergenerational practice in Wales. Here and across the documents, younger people were 
International Journal of Ageing and Later Life

notably absent from discussions of benefits and the purpose of IP. In other instances, younger people were constructed as simply a resource to help older people:

The recognition that discords between the generations is a phenomenon appearing throughout all societies and eras, it deeply depends on social and economic circumstances, and helps us in seeing that young people are receptive to bridge the gap between generations, which social problems such as unemployment, poverty, exclusion and racism make wider. (Document 6, p. 5-6)

Underneath this text was a quarter page-sized image of a young boy holding a globe in his arms. The boy is gazing down at the globe and smiling. Both the extract and the image together constructed younger people as a resource to assist with the social problems outlined. They were not represented as equal in vulnerability or power to older people.

Analysis of the function of the documents provided further evidence that the documents constructed IP as targeted at older people. The majority of documents were published either by all-age organisations or those working with older people. Only one of the 15 documents was published by an organisation working with younger people. This conflicts somewhat with IP definitions, which promote mutual benefits of old and young as a core value. Instead, the publishing of the documents in this way constructed a practice that was for older people and facilitators who work with older people.

The tension between IP as all-age friendly and IP as for older people was evident within documents as well as across them in content and function. The following extract highlights this tension more explicitly:

This strategy has grown out of our Strategy for Older People and, whilst we see it as an essential step in taking intergenerational approaches forward, we recognise that further work needs to be undertaken to ensure that our approach is owned equally by all of the generations. (Document 7, p. 4)

This extract illustrates the difficulties of implementing an all-age friendly IP where both young and old were equal stakeholders in the practice. More often, documents did not reflect on this difficulty and the tension was evident in content that promoted equality within documents positioned for older people's facilitators. 


\section{Process-Focused Evaluation versus Outcome-Focused Evaluation}

All documents made reference to the outcomes of IP and the majority also suggested ways and means of measuring some of the benefits or capturing processes of change. Whilst the benefits that were frequently showcased in the documents were wedded to the process and act of participating in IP, in other instances IP was constructed as outcome-focused and reliant on the measurement of tangible outcomes. One document listed the benefits of IP for older people, younger people and the community. These included: "increased motivation; increased perception of self-worth; improved wellbeing; increased self-esteem and resilience; and, improved community cohesion." (Document 9, p. 5). Similar lists were presented in most documents. Not only were few of the benefits listed concrete and tangible, they also mostly reflected processes of change rather than end goals. There was a sense of IP facilitating personal and collective growth and learning. It was not promoted as a means to an end goal or series of goals. This process of learning and understanding was presented as a core principle of IP.

Equally, great emphasis was placed across the documents on the collection of evidence of success. Outcomes and their measurement were constructed as crucial to IP. Facilitators were reminded of the importance of outcomes:

\footnotetext{
An important note to people using this guideline -

Consultation on the contents of this resource indicated that evaluation has become an increasingly important aspect of IP management for organisations, staff and volunteers working in all sectors if they are to evidence the impact of their work. Evaluation enables projects to discover what works, what doesn't work and how to measure the difference that is being made. This can help with project and business planning and lead to the delivery of better services. It also allows better reporting which means the organisations can be more accountable to funders, stakeholders and to the people who use services. Projects that are not outcome focused will find it extremely challenging to evaluate their value and to evidence this. (Document 2, p. 17)
}

Facilitators were told that projects needed to be outcome-focused in order to gain legitimacy among funders as well as be accountable to all stakeholders, including the communities who participated. Evaluation and evidence were presented as compulsory components, which the future practice and the funding of this depended on. Examples of 
International Journal of Ageing and Later Life

outcomes were usually those tangible and quantifiable outcomes. A pressure to demonstrate "hard outcomes" was recognised in another document under the heading Monitoring and Evaluation:

\footnotetext{
In the 'more for less' environment, the competition for resources is becoming increasingly fierce within and between organisations. Consequently, demonstrating the wider benefits of any policy action is more crucial than ever. In common with many areas of social action based in communities, those advocating Intergenerational Practice at local level will need to address the perceived tensions between what have become known as 'hard' (quantitative) and 'soft' (qualitative) outcomes. (Document 3, p. 12)
}

Despite the inclusion of monitoring in the heading, the emphasis remained on outcomes, rather than processes, and facilitators were cautioned once again to ensure that projects were adequately evidenced. The author did, however, acknowledge and distinguish between quantitative and qualitative outcomes, suggesting that there was a tension between these that would need to be addressed by IP advocates.

\section{Discussion}

Our analysis of IP documents found that IP in the UK is characterised by tensions. IP relies on the contact theory as a mechanism of change which roots IP to an overly individualistic outcome-focused practice targeted at older people. In contrast, the community-led ethos of IP was also evident in the documents alongside values of mutual benefit for old and young, and a desire for more process-focused evaluation. These findings provided empirical support of critical commentaries which suggested that IP needs to be more clearly defined and understood (Granville 2002; Statham2009). These findings also addressed the limitations of other reviews such as Drury et al. (2017), who, in focusing more narrowly on the concept of intergenerational contact, were unable to engage in analysis of broader assumptions and values underpinning practice.

Whilst definitions of IP embraced a community-led ethos, guidance on implementation drew upon a top-down intergroup contact theory-driven approach where the needs and interests of communities were easily lost or obscured. This finding in many ways mirrors the work of Campbell and Cornish (2010) and their four approaches to HIV/AIDS 
interventions ranging from top-down interventionist to a community mobilisation approach. Sykes et al. (2004) demonstrated how the highly individualistic nature of scientific discourse in health promotion hinders its advancement.

The challenge for the future research on IP is to identify how this tension is managed in practice and how facilitators can be supported to develop initiatives that can embrace a community-led approach without being compromised by top-down pressures, which result in intergenerational contact as the focal point of practice.

The tension between IP as targeted at young and old and IP as targeted at older people revealed constructions of who is believed to benefit from the practice. Whilst mutual benefits are at the core of IP definitions, the skewed way in which IP documents were produced contested this definition. IP is in conflict between promoting opportunities for all ages and providing support for older people and this reflects in part the practical challenge of implementing IP in what Hagestad and Uhlenberg (2006) have described as an age-segregated society. The danger of this representation is that it risks neglecting the agency of older people and countering active ageing by constructing older people as dependent upon IP initiatives rather than actively contributing to health promotion. More work therefore needs to be done to promote the benefits of IP to organisations working with younger people to demonstrate what young people can potentially gain from working with older people.

The third tension was identified regarding evaluation of IP; process-focused versus outcomes-focused. Whilst aims of practice referred to processes such as ongoing relationship-building and community participation, practical advice on evidencing the success of initiatives focused, almost exclusively, on tangible quantifiable outcomes. Our findings further suggest that a reliance on the contact theory may be at the root of each of the tensions as, although it provides a simply framework with which to implement and manage practice, it is problematic as it neglects social, political and economic environment within which practice occurs.

The present findings extend previous work by providing a novel critical insight into what IP can achieve (Drury et al. 2017; Granville 2002; Jarrot 2011; Springate et al. 2008). Pressure to provide quantifiable 
International Journal of Ageing and Later Life

evidence resulted in outcome-focused practice, despite attempts to showcase the value of practice processes for communities. This has consequences for those participating in IP who may not benefit or fully engage in the processes advocated. Pressures to be outcome-focused may result in time-limited projects with pre-determined goals and end states, comprising the success of IP from the community's perspective.

Our finding that IP documents were characterised by competing approaches is not unusual. We argue that in making sense of IP as contact-driven, targeted at older people and outcome-focused, the documents legitimise and validate practice as it aligns with institutional cultures across the UK. In mapping IP onto existing institutional structures, agendas and practices that value quantifiable evidence and time-limited projects, the documents provide a more manageable pathway to implementing IP. Through this process, IP is granted familiarity to the practitioners tasked with facilitation. Social representations serve to make familiar the unfamiliar (Moscovici 1988). This representation is highly problematic, because, at best, it distorts the original intention of the practice, and at worst, it directly contradicts it. We found that the documents did also construct IP as community-led, as all-age friendly and process-focused however these representations, which highlighted the values of IP, were in constant tension with representations which better serve IP in practice.

The exclusion of guidelines that did not feature the term "intergenerational" may have resulted in the exclusion of prominent guiding documents for intergenerational work. The rationale behind this final exclusion criterion was the one based on an explicit need to explore "IP"as an emerging practice distinct from other approaches. The broad nature of the sample also resulted in a picture of IP across the UK, potentially neglecting nuances in particular regions or within particular organisations. The most apparent limitation of the present study is the need to assume the usage of the documents sampled. The study did not gather data on the extent to which the documents sampled are used by facilitators. However, the documents sampled were the leading resources available to facilitators across the UK.

Our study has highlighted the need for policy and practice to attend to the ways in which IP guidance may shape and limit practice. The benefits of IP for younger people need to be recognised within policy and 
practice. This recognition may go some way to resist the representation of IP as being an intervention for older people. Furthermore, this may help diversify the communities, activities and scope of IP in terms of content, aims and objectives. Our study has provided further support that policy makers and practitioners need to resist the appeal of and apparent ease of tokenistic intergroup interventions and limited evaluations and "embrace the messiness of real-life social change projects" (Campbell \& Cornish 2014: 11), which requires an understanding of processes as well as outcomes.

To conclude, in treating documents as active agents, rather than static sources of information, the present study has demonstrated the role of IP documents in shaping and constraining the nature of practice. In examining this otherwise taken-for-granted guidance on practice, the present research has addressed calls for a more critical examination of IP as a community health-promotion tool.

\section{Acknowledgements}

The authors would like to thank Keele University, the Beth Johnson Foundation and Stoke-on-Trent Public Health for providing funding to support the research detailed in this article.

\section{Corresponding Author}

Katie Wright-Bevans, School of Psychology, Keele University, Keele ST5 5BG, UK. Email: k.wright.bevans@keele.ac.uk

\section{References}

Abrams, D., Eller, A. \& Bryant, J. (2006). An age apart: The effects of intergenerational contact and stereotype threat on performance and intergroup bias. Psychology \& Aging 21(4):691-702. doi: 10.1037/0882-7974.21.4.691

Alcock, C. L., Camic, P. M., Barker, C., Haridi, C. \& Raven, R. (2011). Intergenerational practice in the community: A focused ethnographic evaluation. Journal of Community \& Applied Social Psychology 21(5): 419-432. doi: 10.1002/casp.1084

Allport, G.W.(1954). The NatureofPrejudice. Cambridge, MA:Addison-Wesley. 
International Journal of Ageing and Later Life

Bernard, M. \& Ellis, S. W. (2004). 'How Do You Know that Intergenerational Practice Works?': A Guide to Getting Started on Evaluating Intergenerational Practice. Stoke-on-Trent: Beth Johnson Foundation.

Beth Johnson Foundation. (2011). A guide to Intergenerational Practice. Stoke-on-Trent: Beth Johnson Foundation.

Braun, V.\&Clarke, V.(2006). Using thematic analysis in psychology.Qualitative Research in Psychology 3(2): 77-101. doi:10.1191/1478088706qp063oa

Brisbois, B. \& Plamondon, K. (2018). The possible worlds of global health research: An ethics-focused discourse analysis. Social Science $\mathcal{E}$ Medicine 196(1): 142-149. doi: 10.1016/j.socscimed.2017.11.034

Buffel, T., McGarry, P., Phillipson, C., De Donder, L., Dury, S., DeWitte, N. \& Verté, D. (2014). Developing age-friendly cities: Case studies from Brussels and Manchester and implications for policy and practice. Journal of Aging E Social Policy 26(1-2): 52-72. doi: 10.1080/08959420.2014.855043

Campbell, C. \& Cornish, F. (2010). Towards a 'fourth generation' of approaches to HIV/AIDS management: Creating contexts for effective community mobilisation. AIDS Care 22(2): 1569-1579. doi: 10.1080/09540121.2010.525812

Campbell, C. \& Cornish, F. (2014). Reimagining community health psychology: Maps, journeys and new terrains. Journal of Health Psychology 19(1): 3-15. doi: 10.1177/1359105313500263

Drury, L., Abrams, D. \& Swift, H. J. (2017). Making Intergenerational Connections - An Evidence Review. London: Age-UK.

Fishbein, M. \& Ajzen, I. (1974). Attitudes towards objects as predictors of single and multiple behavioral criteria. Psychological Review 81(1): 59-74. doi: 10.1037/h0020074

Gaggioli, A., Morganti, L., Bonfiglio, S., Scaratti, C., Cipresso, P., Serino, S. \& Riva, G. (2014). Intergenerational group reminiscence: A potentially effective intervention to enhance elderly psychosocial wellbeing and to improve children's perception of aging. Educational Gerontology 40(7): 486-498. doi: 10.1080/03601277.2013.844042

Granville, G. (2002). A Review of Intergenerational Practice in the UK. Stoke-on-Trent: Beth Johnson Foundation.

Grefe, D. (2011). Combating ageism with narrative and intergroup contact: Possibilities of intergenerational connections. Pastoral Psychology 60(1): 99-105. doi: 10.1007/s11089-010-0280-0 
Hagestad, G. O. \& Uhlenberg, P. (2006). Should we be concerned about age segregation? Some theoretical and empirical explorations. Research on Aging 28(6): 638-653. doi: 10.1177/0164027506291872

Haste, H. (2004). Constructing the citizen. Political Psychology 25(3): 413-439. doi: 10.1111/j.1467-9221.2004.00378.x

Henkin, N. \& Butts, D. (2002). Advancing an intergenerational agenda in the United States. In M. Kaplan, N. Henkin \& A. Kusano (eds.), Linking Lifetimes: A Global View of Intergenerational Exchange (pp. 65-82). Lanham, MD: University Press of America.

Höijer, B. (2011). Social representations theory. A new theory for media research. Nordicom Review 32(2): 3-16. doi: 10.1515/nor-2017-0109

Hewstone, M. \& Swart, H. (2011). Fifty-odd years of inter-group contact: From hypothesis to integrated theory. British Journal of Social Psychology 50(3): 374-386. doi: 10.1111/j.2044-8309.2011.02047.x

Jarrott, S. E. (2011). Where have we been and where are we going? Content analysis of evaluation research of intergenerational programs. Journal of Intergenerational Relationships 9(1): 37-52. doi: 10.1080/15350770.2011.544594

Kalampalikis, N., Bauer, M.W. \& Apostolidis (2013). Science, technology and society: The social representations approach. Revue Internationale de Psychologie Sociale 3(26): 1-232.

Knight, A. (2012). Funding intergenerational initiatives to strengthen local communities. Quality in Ageing and Older Adults 13(4): 307-316. doi: 10.1108/14717791211287011

Kok, G., Schaalma, H., Ruiter, R. A., Van Empelen, P. \& Brug, J. (2004). Intervention mapping: Protocol for applying health psychology theory to prevention programmes. Journal of Health Psychology 9(1): 85-98. doi: $10.1177 / 1359105304038379$

Larkin, E. \& Rosebrook, V. (2002). Standards for intergenerational practice: A proposal. Journal of Early Childhood Teacher Education 23(2): 137-142. doi: 10.1080/1090102020230205

MacCallum, J., Palmer, D., Wright, P. R., Cumming-Potvin, W., Northcote, J. K., Brooker, M. A. \& Tero, C. (2006). Community Building through Intergenerational Exchange Programs: Report to the National Youth Affairs Research Scheme (NYARS). Canberra: Australian Government Department of Families, Community Services \& Indigenous Affairs. 
International Journal of Ageing and Later Life

Maoz, I. (2012). Contact and social change in an ongoing asymmetrical conflict: Four social-psychological models of reconciliation-aimed planned encounters between Israeli Jews and Palestinians. In J. Dixon \& M. Levine (eds.), Beyond Prejudice (pp. 269-85). Cambridge: Cambridge University Press.

Markova, I. (2007). Social identities and social representations: How are they related? In G. Moloney \& I. Walker (eds.), Social Representations and Identity: Content, Process, and power (pp. 215-37). New York: Springer.

Moreno, X., Sánchez, H., Huerta, M., Albala, C. \& Márquez, C. (2016). Social representations of older adults among Chilean elders of three cities with different historical and socio-demographic background. Journal of Cross-Cultural Gerontology 31(2):115-128. doi:10.1007/s10823-016-9288-y

Murray, M. (2014). Social history of health psychology: Context and textbooks. Health Psychology Review 8(2): 215-237. doi: 10.1080/17437199.2012.701058

Murray, M., Pullman, D. \& Rodgers, T. H. (2003). Social representations of health and illness among 'baby-boomers' in eastern Canada. Journal of Health Psychology 8(5): 485-499. doi: 10.1177/13591053030085002

Petersen, A. \& Lupton, D. (1996). The New Public Health: Health and Self in the Age of Risk. London: Sage.

Prior, L. (2003). Using Documents in Social Research. London: Sage.

Prior, L. (2008). Repositioning documents in social research. Sociology 42(5): 821-836. doi: 10.1177/0038038508094564

Sampson, E. L., Bulpitt, C. J. \& Fletcher, A. E. (2009). Survival of community-dwelling older people: The effect of cognitive impairment and social engagement. Journal of the American Geriatrics Society 57(6): 985-991. doi: 10.1111/j.1532-5415.2009.02265.x

Springate, I., Atkinson, M. \& Martin, K. (2008). Intergenerational Practice: A Review of the Literature. LGA Research Report F/SR262. Berkshire: National Foundation for Educational Research.

Statham, E. (2009). Promoting intergenerational programmes: Where is the evidence to inform policy and practice? Evidence E Policy: A Journal of Research, Debate and Practice 5(4): 471-488. doi: 10.1332/174426409X478798

Sykes, C. M., Willig, C. \& Marks, D. F. (2004). Discourses in the European Commission's 1996-2000 health promotion programme. Journal of Health Psychology 9(1): 131-141. doi: 10.1177/1359105304036108 